\title{
Research of Tech Styles in Contemporary Music
}

\section{Cai Wang}

The Education University of Hong Kong

Abstract: The technical methods in the music works are not isolated. They are not only related to the social environment of society and history, but also closely related to the cultural thoughts and musical style of the period. In the mainstream music styles of the 1920s and 1930s, the romantic temperament and the mixed elements of the style are universal in this era. At the same time, with the development of the concerto genre in the 20th century, the inherent form of it also tends to be more flexible. The radical nature of technical language and the traditional nature of expression. It can be said that this duality constitutes Berg's main artistic feature. Innovation under inheritance and development is an important manifestation of the value of music.

Keywords: Berg; Atonality; Romantic Music Elements; Music Inheritance and Development

\section{Assessment criteria of tech styles in contemporary Music}

\subsection{Introduction}

The technical methods in the music works are not isolated. They are not only related to the social environment of society and history, but also closely related to the cultural thoughts and musical style of the period. In the mainstream music styles of the 1920s and 1930s, the romantic temperament and the mixed elements of the style are universal in this era.

At the same time, with the development of the concerto genre in the 20th century, the inherent form of it also tends to be more flexible.

The works of the Austrian composer Alban Berg are generally recognized as having eclectic style characteristics, and his late writing is particularly remarkable.

\subsection{Two research questions}

Question 1: Was Berg's music really atonal?

Question 2: In the perspective of music's development, what is music?

\subsection{Description}

Among the few early works of Berg (generally recognized, the creation before World War I was his early stage, he did not have important works during the war service, and Wozzeck was completed in 1921 after the war was his first. His mature works String Quartet (Op. 3, 1904-1910) has a special status-it is at a turning point in the development of Berg's atonal language. The last song of its previous work Four Songs (Op. 2) gave up the key signature for the first time (Howard Hartog, European Music in the Twentieth Century, Greenwood Press, 1957. p. 98), while in his subsequent work No. 4 Five Orchestral Songs (19121914), he first began writing in Schoenberg's atonal language, and later adopted the twelve-tone system. (Zhong Zilin, Western Music of the 20th Century, Central University for Nationalities Press, 2006 edition, page 23.) Therefore, this work contains a variety of style elements, so that we can observe the context of the Belgian music style, especially the non-tonal language change. Provides an effective window. 
However, was Berg's music really atonal? In his music, it is not difficult to see that the answer is no. In fact, he inherited and developed many elements of romanticism.

Berg's works have some inheritance of traditional tonality, and in many musical elements, he was deeply influenced by Mahler

\subsubsection{Violin Concerto}

This work introduces the Carinthian folk songs, Vienna waltz, and even Bach's hymns, which obviously put tonality in an atonal environment. In dealing with the relationship between the solo and the band, it has the pure characteristics of the romantic concerto from the first to the third movement, retaining many traditional dialogic forms of competition; when the music culminates, especially in the final movement, more symphonic techniques are used, tending to merge various factors. In the aspect of cadenza creation, Berg also has new developments. He transferred the solo cadenza section from the traditional first movement to the third movement, and his cadenza section has a formal status in the whole song, rather than a subsidiary component of the structure. According to the psychological needs of the music process, he arranged a very quiet color band, which also enhanced the skill difficulty in the form of four Canons, while paying attention to the band's small participation and color enhancement.

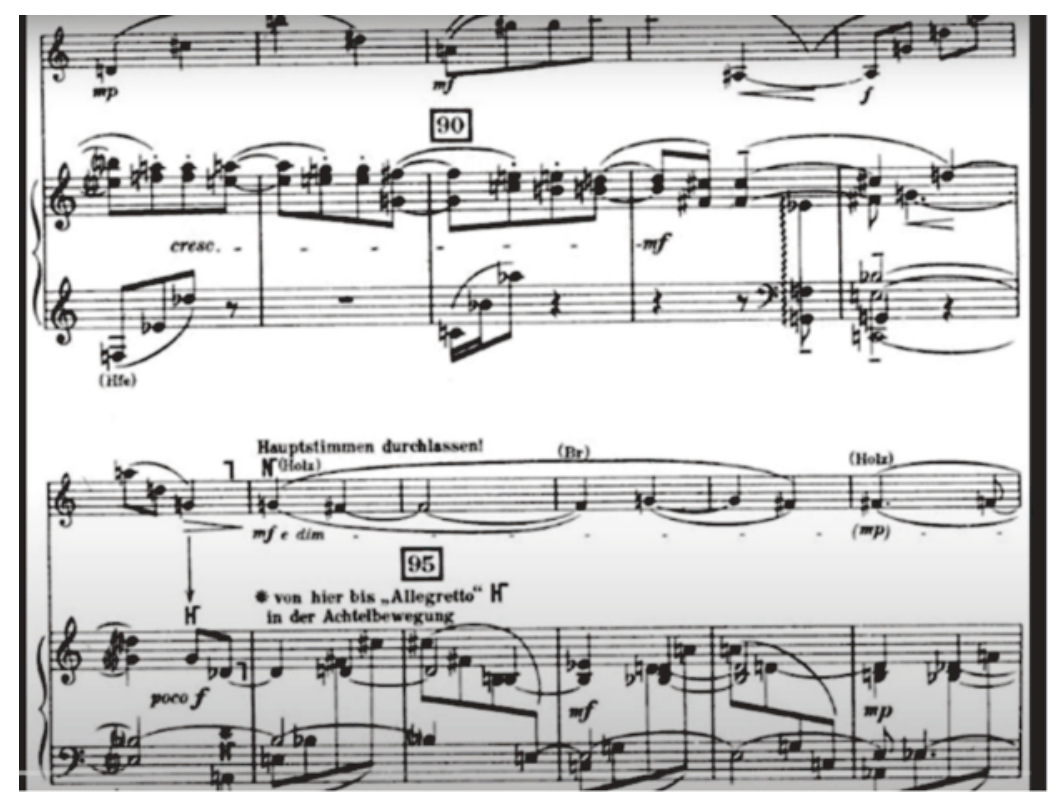

Figure 1. violin concerto.

The source of the score: https://youtu. be/gd0dMs0MTg8

\subsubsection{String Quartet}

Berg's String Quartet was written in 1901 and dedicated to his wife Helen. This song has many inheritance factors for romanticism.

The so-called "inheritance style element" refers to the hint that there are multiple segments in the song that contain the tonal center. Especially in the second movement, the " $D$ " sound seems to have the meaning of "center sound" (even the subtle " $\mathrm{d}$ minor"), which is repeatedly emphasized in this movement. For example: in measures 4-6, the two violin parts are continuously vibrated on the D sound; in the alternating vibrato of the $\mathrm{bE}$ and $\mathrm{D}$ sounds in the violin parts in the 7-8th measure, the $b \mathrm{E}$ sound can be It can be regarded as the front leaning sound of the D sound; in the 66-71 bar, the second violin part is continuously percussion on the D sound, and in the 64-76 bar, the vibration is gradually added ( Main) sound-D sound of the viola part, D sound on the second violin, G sound added again in the viola part, and A sound of the first violin part-just (assumed) $d$ minor (or major) The three functional sounds: $G$ and $A$ are the lower fifth and upper fifth of the $G$ sound respectively; in measures 165-171, the second violin and viola parts continue to play on the D sound again; The 230-231 measure, that is, when the end is near, the first violin part begins to vibrate again on the D sound, and just at the penultimate position of the last measure, the four parts just constitute D Minor third chord-D part of cello part, F part of viola part, A of second violin part, D of the first violin tone portion. After all, this is only Berg's second work to abandon tonality. His exploration of atonal language has just begun. At this time, it is easy to leave some traces of tonality music. In addition, according to scholars' research, there are 
many places in the song that "quoted" the materials of the late romantic composers, such as Wagner's "Tristan"(sections 119142) and Richard Strauss's The Quartet and so on.

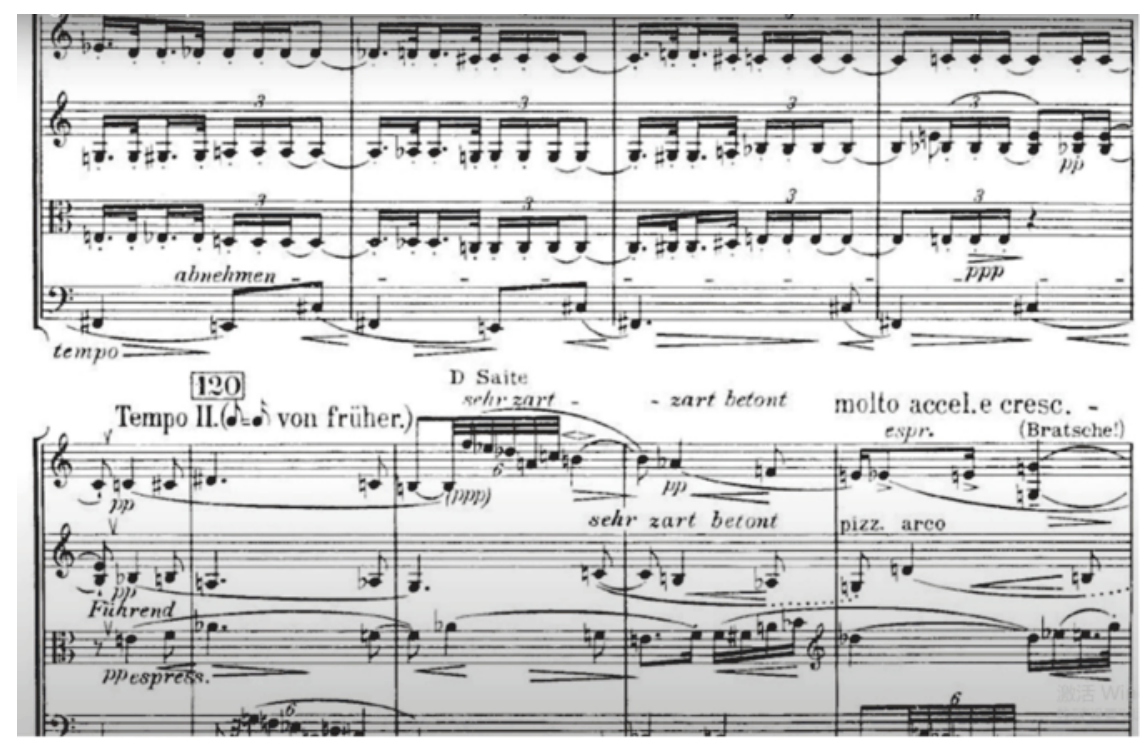

Figure 2. string quartet.

The source of the score: https://youtu. be/mspcyOignc

In addition to the tonal (tonal center) hint, the main motivation or theme transformation techniques used in this song should also be regarded as an inheritance of the tonal tradition. Within the first 11 bars of the first movement, there are at least six core motives: The diatonic "six-tone" motive of the second violin part in bars 1-2 (including an external C), The semitone advancer of the viola and cello parts in measures 2-4, the down-point motive for the second violin part in measures 3-5, and the "pentatonic" motive just entered in the first violin part in measures 7-8. The first three violin part of the first violin part in the 8th to 9th pure "three tone" motives, and the upward "three tone" motive of the first violin part in the 10th to 11th centuries. These motives not only existed in many variations in the first movement, but also penetrated into the second movement in large quantities. During this period, the transformation of motives (reflection, retrograde, expansion, austerity, etc.) had mature precedents early on Hayden, Beethoven, Mozart, Wagner, Liszt, etc., and therefore belonged to inherited style elements.

In addition, the inherited style factors embodied in this song also include the regular adherence to the basic tune of the string quartet. Although the sonata form of the first movement and the roulette form of the second movement are not completely in line with the old norms, but the basic The outline of the frame is there, and it is obvious.

\subsubsection{Berg and Mahler}

Mahler's Ninth Symphony is one of Berg's favorite works. He wrote to Schoenberg and said, “I am completely immersed in Mahler's Ninth Symphony. This is no longer the music of this world, it has mysterious beauty and grandeur. I thought of it on Wednesday and know that it was a mysterious miracle of nature when I heard this kind of music. "(Mitchell Kennedy's "Mahler" Chapter 1, Page 1). Berg discovered through his study of Mahler's Ninth Symphony and found that the Schoenberg School not only belongs to the same field as Mahler in a highly developed background, interest and culture, but also directly inherits Mahler in musical language. Berg also realized that the "Line Part Progress", which was established from the Mahler symphony and broke the traditional harmony language, was here. It gave birth to the polyphonic musical thought that the Schoenberg School attached importance to "Part Part Progress". In this sense, it can be said that Mahler was a pioneer of the Schoenberg School.

Berg also directly quoted materials with special meanings from Mahler's symphony as the basis for his further creation or expression. Redrich's research in Alban-Berg: Its People and Their Music shows that Berg used the symbols in his main works Opera Wozzeck, Lulu and Violin Concerto. The dominant festival symbolizing fate and death is directly quoted from Mahler's "Fate" in Symphony No. 6 and "Death Rhythm” in Symphony No. 9(Mitchell Kennedy's Mahler, page 75 ). Some of the unique expressions used in Mahler's symphony have also been used and played again in Berg's creation. The percussion in the fifth movement of Mahler's Second Symphony (Resurrection), which symbolizes the famous crescendo technique of cracking the earth, Berg used it in the third act of his opera Wozzeck. Mahler used a special mallet in the final movement of 
the Symphony No. 6 that symbolizes the fate of his three hits and Berg used it directly in the third of his Three Orchestras. The tonal d minor of the first movement of the Symphony No. 9 is in some of Berg's early songs, the middle of the first two songs of the second work, the second movement of the String Quartet, and the Wozzeck's third interlude and the concert aria Wine are frequently used, which has almost become a special tonal center of Berg. In these works I heard Webern's sparse, fragmented texture, Berg's aphorisms, concise style, Schoenberg's overall theme system and the fragmentation of the theme group in Mahler's Ninth Symphony, and the technique was later carried forward by Webern and Berg.

We can also find that the title of Berg's works is extremely distinctive. The title is the product of the romantic period, especially in the highly developed romantic music in the late period, the composers are most passionate about the themes of pain, death, and fate. Moreover, he often describes his personal emotional experience in music. Lyric Suite is titled and its secret contributor is his lover Hanna. Violin Concerto is also clearly titled, not only involving the death of the young girl Manon, but also containing the "secret title". Judging from the arrangement of the expressions and tempo of the four movements, it is obviously also quite dramatic. At this point, Berg is also closer to Mahler than Schoenberg, and tends to imply implicit headline content that is not clearly indicated. In a sense, all Berg's works can be said to be title in form and content. Stravinsky also pointed out when talking about Berg:

Berg's form has a title (in this respect, and in many other respects, he is opposite to Webern); the structure of the title is the essence of his composition method, and the autonomy of his form is determined by this. No matter how complicated his form is, it is a "mathematical formula", which is the always "free" title structure produced by "feeling" and "representation".

\subsubsection{Wozzeck and Lulu}

"Sense of form" is Berg's creative tendency. His work No. 1 Piano Sonata reflects this tendency, and this rigorous "sense of form" is clearly demonstrated in almost all Berg's works. The most prominent example is of course his three-act opera Wozzeck. Wozzeck intentionally uses suites, rhapsody, march, lullaby, passacaglia, quasi-rondo, symphony, sonata, fantasia and fugue, harmonies, creative songs and so on(Zhong Zilin, 20th Century Western Music, Central University for Nationalities Press, 2006 edition, p. 23.) as a need to cooperate with the plot and the high order in the form and structure of stage works realized by performance is amazing, and it is like "lyric style". As we all know, this is one of the important characteristics of Berg's musical style, and it is also the main reason that makes his works most "audible" and easy to be accepted by listeners in many modern music.

Berg's Wozzeck and the later unfinished Lulu took expressionist musical art to the peak, but the work between the two operas was not very radical. They just carry elements of expressionist music.

Whether Berg's creation uses technically atonal or twelve-tone language, there is some romantic music in the overall intuitive feeling. The radical nature of technical language and the traditional nature of expression. It can be said that this duality constitutes Berg's main artistic feature.

\subsection{Reasoning}

In fact, due to the similarity of cultural background, psychological characteristics and fate, the music of the New Vienna School and Mahler are extremely close in spirit. In terms of creative concept, Schoenberg believes that "The greatest goal pursued by an artist is only one: To express himself. If this is achieved, then the artist has already achieved a great success."(Hansen, 20th Century Music Introduction Part 1 Beijing People’s Music Publishing House, September 1981), and he also believed that "Mahler is a man who faithfully expresses himself".

Schoenberg's early Gurrelieder showed in many ways that he was influenced by Mahler, and he still kept in touch with Mahler after the style transformation.

Berg's respect for Mahler is particularly remarkable, even reflected in all aspects of his life. Compared with Schoenberg and Webern, his works have more Mahler-like marks. Berg's Three Orchestral Music has been greatly influenced by Mahler in terms of tragic musical tone, symbolic rhythm of fate, and emphasis on tonal factors. When talking about the third March of the work, Berg himself said that the song sounds “as if it were Schoenberg's Five Orchestral Pieces" and Mahler's Ninth Symphony playing together".

\subsection{Arguments}

Berg has always sought a balance between tonality and twelve notes. His treatment of twelve-note technique is far more free than that of Schoenberg and Wilbur. In traditional thinking, twelve-tone music is mechanical and emotionless. However, 
the twelve-tone technique is only a means, and different composers have their own opinions on the grasp of musical style. Berg is a composer who often blends personal experiences and emotions into music. For him, music must express clear content. Berg has never been a "systematic" composer, and has never been bound by a theory or a theory. In fact, his application of twelvetone technique has never changed his inherent musical style and some of his usual methods of composition. Therefore, even with the twelve-tone composition, we can still see traces of traditional music in his works.

Because of this, it is not difficult for us to feel the strong romanticism in Berg's works. In the combination of twelvetone technique and traditional music, he created a completely new musical language of his own, adding more emotional power and elegant colors to expressionist music. He combined Schoenberg's boring composition method with emotional expression, so that this new and more abstract language can also express human emotions and give people artistic appeal. Berg's representative works. Berg was by no means a stalwart of romanticism, but he never broke away from romanticism.

Although he uses atonality and twelve tones as the composition of his musical language, the long melody lines and continuous breath that he is good at, make the overall musical flavor and expression of the work appear romantic. Among the highly developed romantic music in the late period, the composers are most passionate about the themes of pain, death, fate, etc., and Berg also often describes private emotional experiences in music.

\subsection{Discussion}

Some research on Berg's work has led me to a question: How to view the relationship between 20th-century modern music and past music, or from the perspective of music development, is the past music style still being used for reference? This is a problem that haunts my mind all the time. Violin Concerto is by no means a special case, and Berg is not the first person to face this creative problem.

Stravinsky created a work of the same genre Violin Concerto in D major, which also did not inherit the traditional concerto three movements.

The four movements to be replaced are: Tokata, Aria I, Aria II and Caprice One. Such a movement pattern and title are reminiscent of Bach, but in fact, its music material is not necessarily related to Bach.

Stravinsky's music always incorporates changes in a natural music system. Even if Stravinsky quoted materials from the Baroque or Classicist period, it is indeed possible to find the shadows of clear Mozart and Pergolesi in some melodies, but he did not join in the harmony. As a result, he re-identified the nature of these genres, thereby generating new ways of viewing. The style he formed did not belong to the objects he borrowed from, but only to himself. As a result, Stravinsky has a unique "style mix".

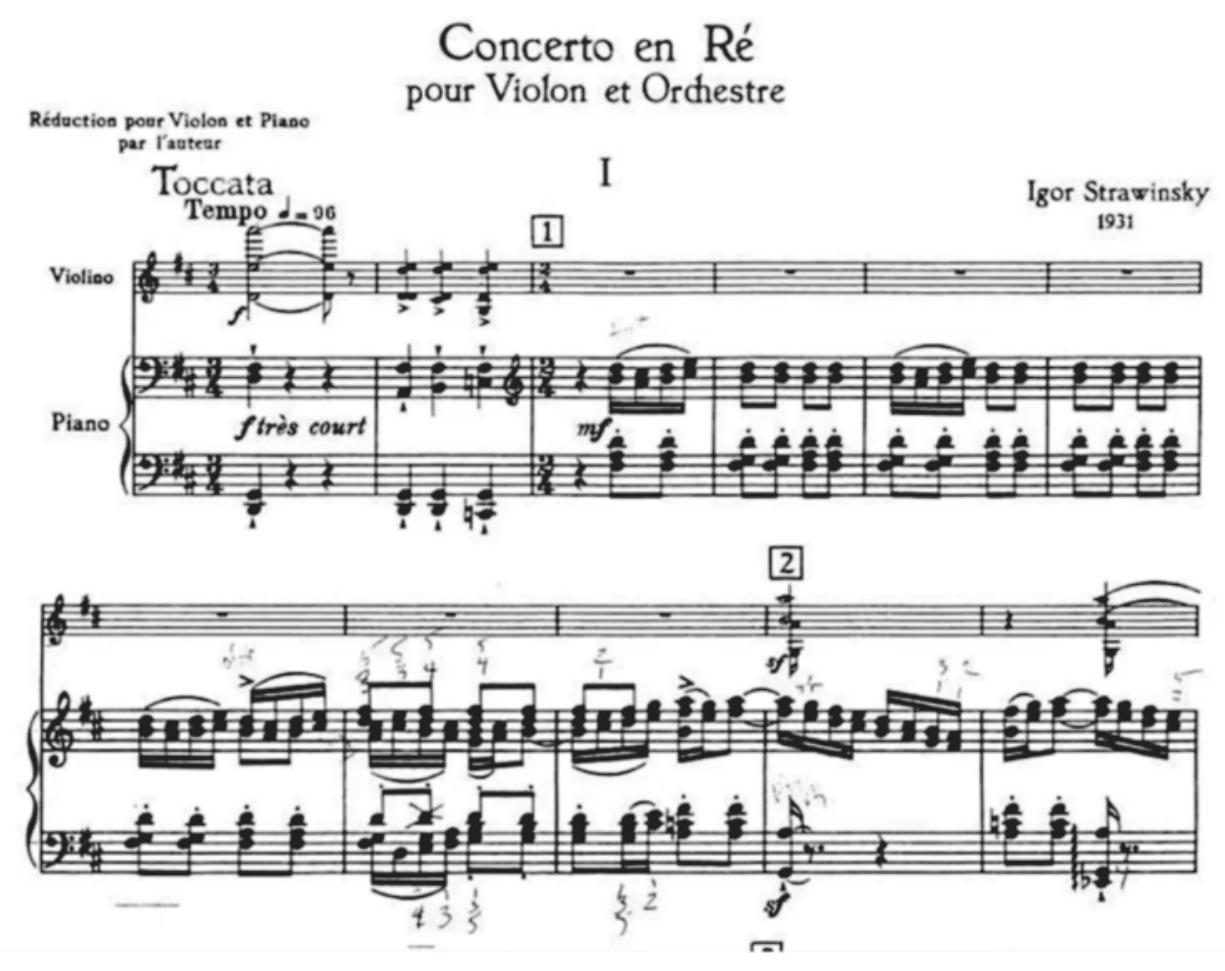

Figure 3. violin concerto in D.

The source of the score: https://youtu. be/zVguPTpxoEU 


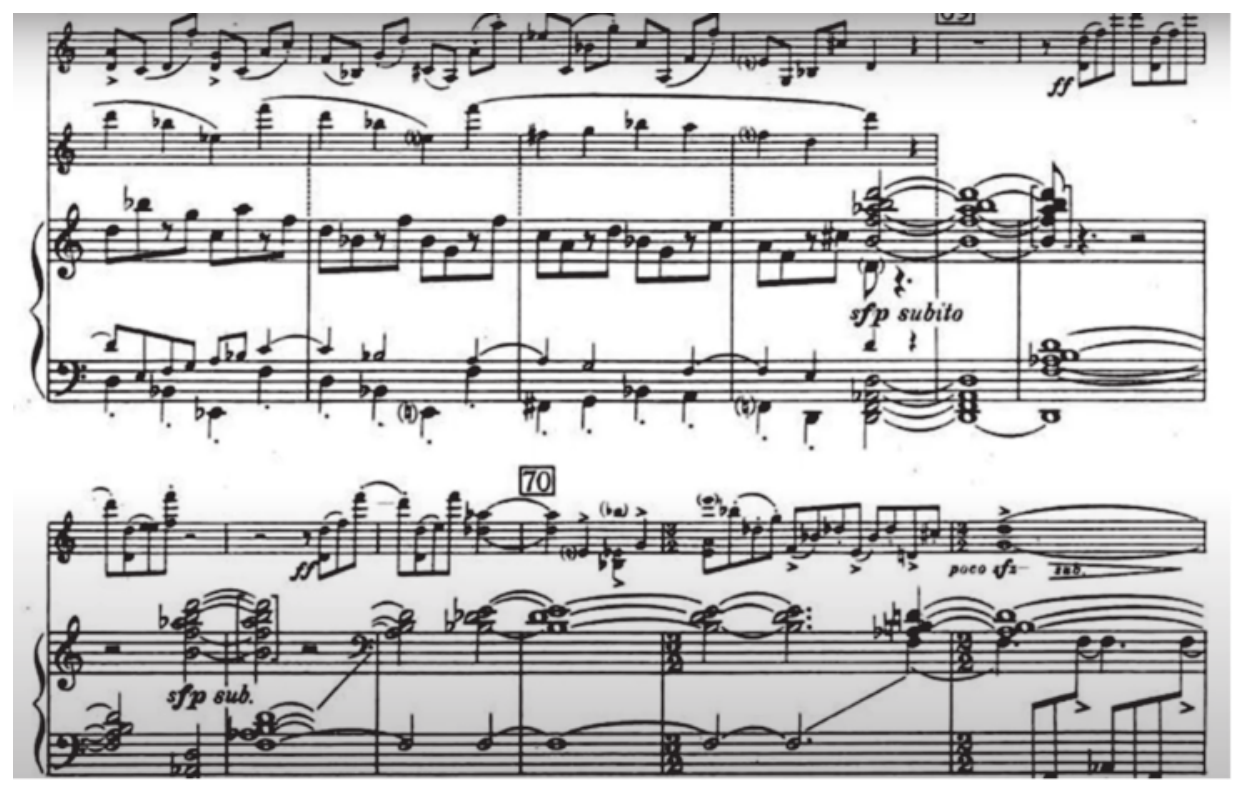

Figure 4. another part of violin concerto in D.

The source of the score: https://youtu. be/zVguPTpxoEU

We can see that its melody is traditional, but the harmony uses modern techniques.

\section{Conclusion}

In the history of music, not only the composers of the 20th century, but every composer of all ages has never stopped thinking about this issue. They all express their relationship to the past in their music in some way, whether conscious or unconscious.

To sum up, from the perspective of music development, what is music?

In my opinion, the formation of the work style is not just a purely subjective product of the composer, but a result of being selected by the historical language and social environment and choosing among the musical languages given by history. Berg, like other composers at the time, had to face the unavoidable problem of composition, that is, to make choices among the many musical thoughts that haunted them. Berg is good at reintegrating various elements and using it for himself, creating musical masterpieces with eclectic style characteristics. Innovation under inheritance and development is an important manifestation of the value of music.

\section{References}

1. Zhong ZL, 20th century western music. Central University for Nationalities Press; 2006.

2. Shen X. Compendium of western music history. Shanghai Music Press 1999: 367.

3. Yu ZG, “Alban Berg's life and creation road”. Central Conservatory of Music Press 2003: 43.

4. Howard H. European music in the twentieth century. Greenwood Press; 1957. 